\title{
Effects of feeding level on efficiency of high and low residual feed intake beef steers.
}

ASAS EDITORIAL

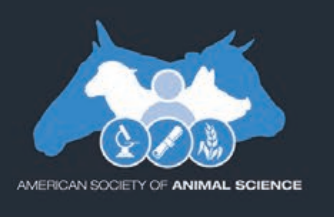

Feed is a major cost factor in beef production. Cattle that metabolize feed more efficiently can therefore improve profits and reduce resource use.

Climate change is expected to exacerbate

disruptions in feed supply (e.g., via

drought), therefore there is interest in

selecting the most efficient animals.

However, it is unclear whether steers with a low RFI (residual feed intake -a measure of the animal's baseline feed efficiency) also remain more efficient when feed is restricted.

LOWER HEAT PRODUCTION LOWER MAINTENANCE ENERGY
GREATER HEAT PRODUCTION GREATER MAINTENANCE ENERGY

The energy requirements of high RFI and low RFI steers were compared after a period of free access to feed followed by a period of restricted feed intake:

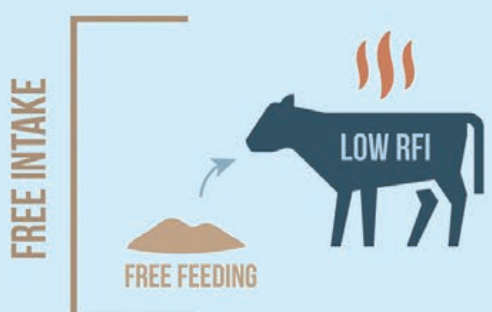

\section{LESS FEED CONSUMED}

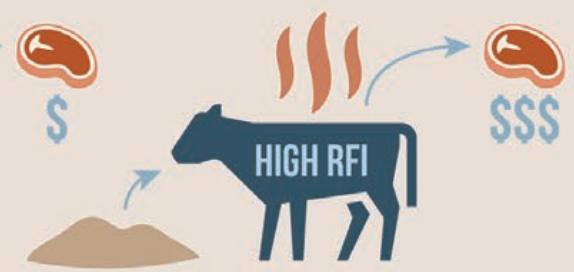

MORE FEED CONSUMED
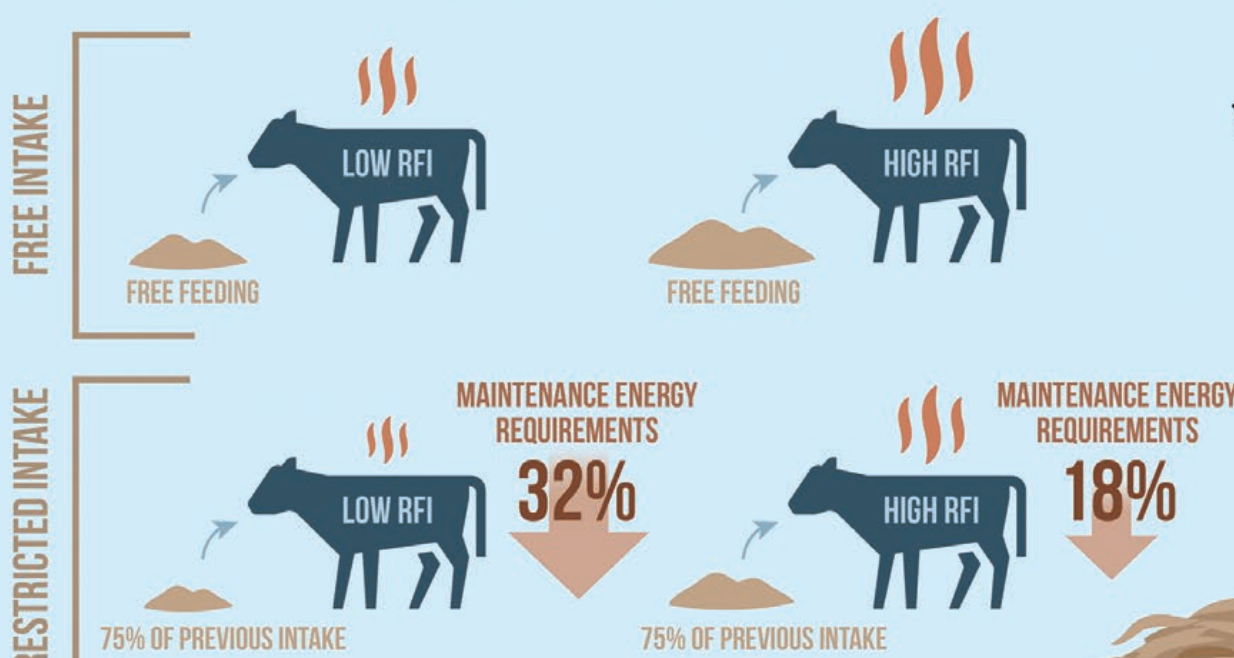

After feed was restricted, both groups used less energy, however the low RFI steers decreased their energy requirements more than the high RFI steers.
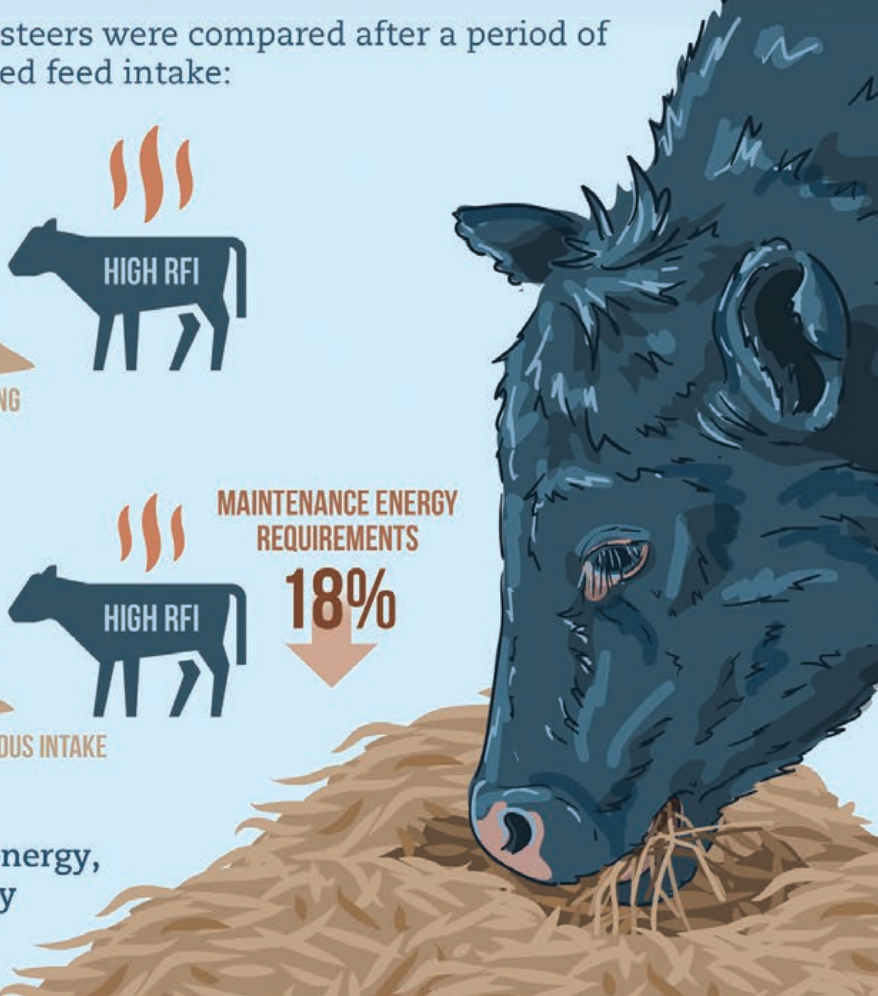


\section{INFOGRAPHIC}

\section{Effects of feeding level on efficiency of high and low residual feed intake beef steers}

The physiological basis for differences in beef cattle feed efficiency, as defined by residual feed intake (RFI), has been explored extensively. Divergent RFI may be partially explained by differences in nutrient digestibility and rumen volatile fatty acid production (Johnson et al., 2019), feeding behavior (Parsons et al., 2020), and intestinal microbiome composition (Welch et al., 2020). With increasing concerns regarding climate change and narrow profit margins, a recent paper examined efficiency parameters in feed-restricted beef steers (Andreini et al., 2020). Results point to conserved mechanisms underlying low RFI which may be a cost benefit for producers experiencing fewer feed resources.

\section{References}

Andreini, E. M., S. M. Augenstein, C. S. Fales, R. D. Sainz, and J. W. Oltjen. 2020. Effects of feeding level on efficiency of high and low residual feed intake beef steers. J. Anim. Sci. 98:1-9. doi:10.1093/jas/skaa286

Johnson, J. R., G. E. Carstens, W. K. Krueger, P. A. Lancaster, E. G. Brown, L. O. Tedeschi, R. C. Anderson, K. A. Johnson, and A. Brosh. 2019. Associations between residual feed intake and apparent nutrient digestibility, in vitro methane-producing activity, and volatile fatty acid concentrations in growing beef cattle. J Anim Sci. 97:3550-3561. doi:10.1093/jas/skz195

Parsons, I. L., J. R. Johnson, W. C. Kayser, L. O. Tedeschi, and G. E. Carstens. 2020. Characterization of feeding behavior traits in steers with divergent residual feed intake consuming a high-concentrate diet. J Anim Sci. 98:1-9. doi:10.1093/jas/ skaa189

Welch, C. B.,J. M. Lourenco, D. B. Davis,T. R. Krause,M. N. Carmichael, M. J. Rothrock, T. D. Pringle, and T. R. Callaway. 2020. The impact of feed efficiency selection on the ruminal, cecal, and fecal microbiomes of Angus steers from a commercial feedlot. $J$ Anim Sci. 98:1-10. doi:10.1093/jas/skaa230 